\title{
DAMPAK PENERAPAN GOOD UNIVERSITY GOVERNANCE TERHADAP KINERJA MANAJERIAL MELALUI IMPLEMENTASI ANGGARAN BERBASIS PARTISIPATIF
}

\author{
Amilin \\ Fakultas Ekonomi dan Bisnis UIN Syarif Hidayatullah Jakarta \\ E-mail: amilin@uinjkt.ac.id
}

\begin{abstract}
The purpose of this study to examine the impact of the implementation of Good University Governance Principles on managerial performance in the practice of participatory-based budget management. The units in UIN Syarif Hidayatullah Jakarta as the population of the study.Samples were selected from the units that perform a budget management. The number of respondents, 60 people who have a structural position in around UIN Syarif Hidayatullah Jakarta who served as: Vice-Chancellor, Vice Dean, Head of Departement, Bureau Chief, Head of Division, Chief of Section, Directorate of Internal Control System. Testing data using a Path Analysis Method. The results of the study are: First, the application of Good University Governance Principles at UIN Syarif Hidayatullah Jakarta influence onmanagerial performance; and Second,the practice of participatory-based budget managementat UIN Syarif Hidayatullah Jakarta have not been able to encourage the application of Good University Governance Principles in influencing managerial performance. The results of the study is important for university officials as a reference in a practice of participatory-based budget managementby applying Good University Governance principles to achieve the best performance.
\end{abstract}

Keywords: good university governance, participatory budgeting, managerial performance, UIN Syarif Hidayatullah Jakarta

Abstrak. Tujuan penelitian ini untuk menguji secara empiris tentang dampak penerapan prinsip-prinsip Good University Governance terhadap kinerja manajerial dalam praktik pengelolaan anggaran berbasis partisipatif. Populasi penelitian ini adalah unit-unit kerja yang ada di lingkungan UIN Syarif Hidayatullah Jakarta. Sampel yang dipilih dalam penelitian ini adalah unit-unit kerja yang melakukan pengelolaan anggaran. Responden penelitian sebanyak 60 orang yang memiliki jabatan struktural di lingkungan kampus UIN Syarif Hidayatullah Jakarta dengan posisi jabatan sebagai: Wakil Rektor, Wakil Dekan, Ketua Program Studi, Kepala Biro, Kepala Bagian, Kepala Sub Bagian, Direktorat Sistem Pengendalian Intern. Pengujian data untuk menjawab hipotesis menggunakan metoda analisis jalur. Hasil penelitian ini antara lain: Pertama,penerapan prinsip-prinsip Good University Governance di UIN Syarif Hidayatullah Jakarta berpengaruh terhadap kinerja manajerial; dan Kedua, praktik pengelolaan anggaran berbasis partisipatif di UIN Syarif Hidayatullah Jakarta belum dapat mendorong penerapan prinsip-prinsip Good University Governance dalam mempengaruhi kinerja manajerial.

Kata Kunci: good university governance, participatory budgeting, managerial performance, UIN Syarif Hidayatullah Jakarta 


\section{PENDAHULUAN}

Good University Governance(GUG) merupakan konsep yang diadopsi dari Good Corporate Governance (GCG). Saat ini, studitentang Corporate Governancebukanlah sebuah isu baru jika dibandingkan dengan isu mengenai University Governance, karena studi sebelumnya tentang Good University Governancebelum banyak dipublikasikan. Isu dan studi mengenai Corporate Governance telah banyak menyita perhatian para CEO perusahaan sejak era 1990-an dan menjadi sangat populer setelah terjadi kasus runtuhnya Enron and World.com di awal tahun 2000-an. Lain halnya dengan studi tentang Corporate Governance, studi tentang University Governancetidak didahului dengan sebuah peristiwa penting tentang kebangkrutan sebuah perguruan tinggi.Beberapa peneliti berargumentasi bahwa Corporate Governancememegang peran penting dalam pengawasan perusahaan (Fama, 1980; Fama \& Jensen 1983). Begitu juga studi tentang university governance memberikan kontribusi penting bagi para pengelola perguruan tinggi sebagai salah satu referensi dalam mengelola perguruan tinggi (Wijanto, 2009).

Diskusi tentang GCG atau GUG tentu tidak terpisah dari isu mengenai partisipasi dalam praktik proses penyusunan anggaran.Praktik ini merupakan kegiatan pertanggungjawaban dalam sistem pengendalian manajemen dan telah menjadi subyek pengujian cross-cultural. Salah satu studi yang membuktikan hal tersebut dengan menggunakan konsep Hofstede's (1980) misalnyaHwang (1989).Hwang (1989) melakukan studi terhadap para manajer di Australia untuk menguji pengaruh budaya nasional terhadap hubungan antara partisipasi anggaran dengan motivasi kerja.Hasil studinya menunjukkan bahwa partisipasi dalam proses penyusunan anggaran memiliki hubungan positif dengan komponen model motivasi House's (1971).

Hubungan penganggaran partisipatif dan kinerja manajerial sudah sejak lama menjadi isu penting dalam riset-riset bidang organisasi. Ini menjadi salah satu alasan mengapa hubungan tersebut menjadi perhatian bagi banyak studi di bidang organisasi selama lebih dari 50 tahun sejak pertama kali diteliti oleh Argyris (1952).Argumentasi ini diperkuat oleh Syakhroza (2003) yang menyatakan bahwa penelitian tentang pengelolaan anggaran telah berkembang kedalam beberapa bidang yaitu: bidang ekonomi, psikologi, sosial maupun politik. Jika dikaitkan dengan penelitian tentang perilaku,topik penelitian tentang anggaran banyak merujuk pada hasil studi yang dilakukan oleh Argyis (1952).

Selain studi Argyris (1952), beberapa studi sebelumnya yang menguji tentang pengaruh penganggaran partisipatif terhadap kinerja yang dilakukan di Amerika Serikat antara lain:Brownell (1982) dan Kren (1992).Studi yang dilakukan di Asia antara lain oleh: Birnberg \&Snodgrass(1988), Chow et al.(1991), Harrison(1992), Tsui (2001), Ueno \& Sekaran(1992). Studi-studi tersebut dipicu oleh perkembangan terknologi informasi dan komunikasi mengenai pentingnya peran partisipasi dalam proses penyusunan anggaran ketika dihubungkan dengan kinerja manajerial. Hasil studi Hopwood (1976) memperkuat hasil-hasil studitersebut yang menunjukkanbukti bahwa partisipasi manajer dalam proses penganggaran merupakan mekanisme dalam mengumpulkan dan mengolah informasi tambahan sebagai referensi untuk mengambil keputusan.

Dalam rangka mengembangkan hasil-hasil studi sebelumnya,penelitian ini bermaksud melakukan pengujian tentang pengaruh implementasi Good University Governancepada sebuah universitas di Indonesia terhadap kinerja manajemen dengan penganggaran partisipatif sebagai variabel intervening.Studi ini sangat penting dilakukan pada lembaga pendidikan tinggi di Indonesia mengingat perannya yang sangat strategis 
dalam memberikan pelayanan di bidang pendidikan kepada para pemangku kepentingan khususnya mahasiswa. Hasil studi ini diuraikan dengan sistematika sebagai berikut: Bagian pertama, menjelaskan tentang latar belakang, tujuan dan alasan pentingnya penelitian ini dilakukan. Bagian kedua, menjelaskan tentang tinjauan teori dan pengembangan hipotesis. Bagian ketiga, menjelaskan tentang populasi dan metode pemilihan sampel, horison waktu penelitian, operasionaliasi variabel penelitian, dan metode pengujian hipotesis. Bagian keempat, menjelaskan tentang hasil penelitian dan pembahasan. Bagian terakhir, menjelaskan tentang kesimpulan, keterbatasan dan rekomendasi untukpenelitianselanjutnya.

\section{KAJIAN TEORI}

Good University Governance. Kegiatan pengelolaan anggaran tidak lepas dari kegiatan tata kelola (governance) sebuah organisasi. Dengan konsep good governance, tata kelola perguruan tinggi yang baik (Good University Governance)relevan dengan prinsip Good Corporate Governance $(G C G)$. Prinsip-prinsip tersebut meliputi: transparansi, akuntabilitas, responsibilitas, independensi, dan keadilan. Prinsip GCG tersebut dapat diterapkan dalam mengelola sebuah perguruan tinggi (Wijatno, 2009). Good governance juga memberikan sebuah struktur yang dapat memfasilitasi penentuan sasaran-sasaran organisasi, sekaligus sebagai sarana untuk menentukan teknik monitoring kinerja manajerial(Darmawati, Khomsiyah dan Rahayu, 2004).

Penganggaran Partisipatif. Penganggaran partisipatif merupakan sebuah metode penyusunan anggaran yang meliputi proses pengambilan keputusan bersama, dan semua bagian setuju atas target anggaran yang ingin dicapai (Atkinson\& Atkinson, 1997). Proses partisipasi dalam penyusunan anggaran merupakan keikutsertaan semua manajer dalam proses penyusunan anggaran organisasi termasuk pada saat membuat keputusan.Penyusunan anggaran partisipatif dimulai dari tingkat manajer yang paling rendah sampai pada level tertinggi (Antony dan Govidarajan, 2004).Pendapat lain yang dikemukakan oleh Kaplan \&Cooper(1998)menyatakan bahwa penganggaran partisipatif merupakan teknik yang memberikan kesempatan pada individu untuk bertanggungjawab atas kinerja dalam pelaksanaan anggaran, dan turut berperan serta dalam pengambilan keputusan sehubungan dengan proses penyusunan dan pelaksanaannya.

Managerial Performance. Definisi kinerja majerial menurut Ferris (1977) yaitu sejauh mana peran pencapaian sukses dapat dicapai.Milani (1975) mendefinisikan kinerja manajerial sebagai persentase pencapaian tujuan dan jumlah jam produktif. Sedangkan Ivancevich (1979) mendefiniskan kinerja manajerial sebagai kualitas kerja yang dilakukan, memenuhi jadwal biaya dan memenuhi tenggat waktu proyek.Definisi kinerja manajerial dalam penelitian ini mengacu pada definisi yang disampaikan Ferris (1977).

Goal Theorydalam Perspektif Anggaran dan Kinerja. Berdasarkan teori goal-setting, dapat dijelaskan bahwa keterlibatan manajer dalam proses penganggaran mempengaruhi harapan atas outcome, yang akan diterima. Partisipasi dalam penyusunan anggaran bertujuan untuk membentuk sikap perilaku karyawan dan manajer. Partisipasi dapat mendorong manajer untuk mengidentifikasi tujuan, menerimanya dengan suatu komitmen 
dan bekerja dengan sebaik-baiknya untuk mencapai kinerja manajerial yang optimal(Wentzel, 2002; Clinton dan Hunton, 2001;Otley, 1978; Dunk, 1993; Chong dan Chong, 2002).

Kerangka Pemikiran dan Hipotesis Penelitian. Dalam kaitannya dengan Good University Governance, Wijatno (2009) menyatakan bahwa perguruan tinggi harus dapat menerapkan prinsip keterbukaan di bidang keuangan, prosedur dan sistem penerimaan mahasiswa baru, sistem akuntansi dan pelaporan keuangan, rekruitmen dosen dan karyawan, pemilihan pejabat struktural, pemilihan anggota senat, dan informasi-informasi penting lainnya kepada pemangku kepentingan secara memadai, akurat, dan tepat waktu. Selain itu, setiap individu yang terlibat dalam pengelolaan perguruan tinggi harus bertanggungjawab atas segata tindakannya sesuai dengan job description yang telah ditetapkan,termasuk para dosen harus mentaati etika dan norma akademik. Uraian pendapat tersebut merupakan bagian dari pelaksanaan prinsip-prinsip Good University Governance.

Kaitannya dengan masalah kinerja manajerial, pengelolaan anggaran di perguruan tinggi harus selaras dengan prinsip-prinsip Good University Governanceagar dapat mendorong pencapaian kinerja manajerial yang terbaik. Hasil kajian yang dilakukan Utomo (2006)menunjukkan bukti empiris bawah apabila partisipasi anggaran tidak dilaksanakan dengan baik maka dapat mendorong terjadinya senjangan anggaran. Temuan ini berimplikasi negatif terhadap evaluasi kinerja bawahan pada unit pertanggungjawaban mereka (Dunk dan Nouri, 1998). Studi lainnya yang dilakukan oleh Fisher, Frederickson dan Peffer (2000) menemukan bahwa empiris bahwa dalam kondisi informasi asimetris dapat terjadi senjangan anggaran yang lebih besar.

Diskusi tentang partisipasi anggaran,seringkali banyak dihubungkan dengan budgetary slack (senjangan anggaran) dan ditemukan terdapat pengaruh yang tidak konsisten. Hasil kajian yang dilakukan oleh Dunk dan Perera (1996)misalnya, ditemukan bahwa sebenarnya bukan partisipasi dalam penganggaran atau asimetri informasi yang mempengaruhi budgetary slack tetapi faktor personal dari pembuat anggaran itu sendiri. Peneliti lainnya, Steven (2002) menemukan bukti empiris bahwa bawahan mengasosiasikan slack sebagai mis-interpretasi atau ketidakjujuran yang menekan bawahan untuk mengurangi slack. Sedangkan Blanchette, et. al., (2002) menemukan hal yang sebaliknya yaitu bawahan menganggap budgetary slack berpengaruh positif, sehingga bawahan cenderung untuk menaikkan budgetary slack.

Proses penyusunan anggaran suatu organisasi merupakan kegiatan yang penting dan sekaligus komplek, karena anggaran mempunyai dampak fungsional terhadap sikap dan perilaku anggota organisasi (Argyris, 1952; Milani, 1975). Partisipasi semua lapisan manajer secara luas pada dasarnya merupakan proses organisasional, para anggota organisasi terlibat dalam proses pembuatan keputusan. Partisipasi dalam konteks penyusunan anggaran merupakan proses evaluasi kinerja individu yang dihargai berdasarkan pencapaian anggaran, sehingga berpengaruh dalam menyusun target capaian realisasi anggaran (Brownell, 1992).

Penganggaran partisipatif merupakan anggaran yang dipersiapkan secara bersama dengan melibatkan para manajer pada semua level (Gorrison dan Noreen 2003). Kinerja manajerial merupakan salah satu faktor yang dapat meningkatkan efektivitas organisasi dalam mencapai tujuannya. Menurut Mahoney et. al. (1963), kinerja manajerial adalah kinerja tiap individu anggota organisasi dalam kegiatan-kegiatan manajerial, antara 
lain:perencanaan, investigasi, koordinasi, supervisi, pengaturan staf, negosiasi dan representasi.

Pengaruh penganggaran partisipatif terhadap kinerja manajerial merupakan tema pokok yang menarik dalam penelitian akuntansi manajemen. Dalam hal ini Brownell (1982) menyebutkan dua alasan yaitu: (1) partisipasi pada umumnya dinilai sebagai pendekatan manajerial yang dapat meningkatkan kinerja anggota organisasi, dan (2) berbagai penelitian yang menguji hubungan antara partisipasi dengan kinerja diperoleh hasil yang tidak konsisten.Penelitian lainnya yang menunjukkan bahwa anggaran patisipatif berhubungan positif terhadap kinerja manajerial dan kepuasan kerja antara lain adalah Brownel dan McInnes (1986), Shield et al. (2000), Wentzel (2002).Penelitian di Indonesia salah satunya dilakukan oleh Indriantoro (1993) terhadap 170 orang manajer. Dari hasil penelitian lndriantoro (1993)tersebut dapat diketahui bahwa gaya seorang pemimpin dapat mempengaruhi proses penyusunan anggaran. Selanjutnya,Yenti (2003) meneliti terhadap 1000 orang manajer pada perusahaan manufaktur go public. Hasil penelitian tersebut menemukan adanya hubungan positip dan signifikan antara partisipasi dalam menyusun anggaran dengan kinerja manajerial.Berdasarkan kerangka pemikiran yang dipaparkan pada bagian sebelumnya, maka dapat dirumuskan hipotesis sebagai berikut:

$\mathrm{H}_{\mathrm{a} 1}$ : Penerapan prinsip-prinsip Good University Governance berpengaruh terhadap kinerja manajerial.

$\mathrm{H}_{\mathrm{a} 2}$ : Penerapan prinsip-prinsip Good University Governance berpengaruh terhadap kinerja manajerial melalui praktik pengelolaan anggaran berbasis partisipatif sebagai variabel intervening.

\section{METODE}

Populasi, Metode Pemilihan Sampel, dan Pengukuran Variabel. Populasi penelitian ini adalah semua unit kerja yang ada di lingkungan UIN Syarif Hidayatullah Jakarta. Sedangkan sampel yang digunakan dalam penelitian ini adalah unit-unit kerja yang melakukan pengelolaan anggaran. Teknik pengumpulan data menggunakan kuesioner. Responden yang berpartisipasi dalam penelitian ini mulai dari ketua lembaga dan ketua Program Studi di tingkat Fakultas hingga pejabat di tingkat rektorat yang bertanggungjawab dalam menyusun dan mengelola anggaran pada masing-masing tingkatan unit kerja. Pemilihan sampel dengan menggunakan metode Convenience Sampling. Alasan penggunaan metode ini didasarkan pada kemudahan dan kepraktisan dalam memilih sampel.Periode penelitian dilakukan tanggal 19 Agustus 2015 sampai dengan tanggal 19 Oktober 2015. Variabel Prinsip-Prinsip Good University Governance diukur dengan 5 item pertanyaan yang diukur meunggunakan Skala Likert 5 poin. Variabel Praktik Pengelolaan Anggaran Berbasis Partisipatif diukur dengan 6 item pertanyaanmenggunakan Skala Likert 5 poin. Variabel Kinerja Manajerial diukur dengan 9 item pertanyaanmenggunakan Skala Likert 5 poin.

Metode Analisis Data. Data diuji menggunakan uji statistik deskriptif dan uji kualitas data. Pengujian statistik deskriptif terdiri dari: jumlah data (sum), data maksimum, data minimum, data rata-rata (mean), dan data deviasi standar.Sedangkan pengujian kualitas data terdiri dari uji validitas dan reliabilitas data. Uji validitas dilakukan dengancara 
menghitung korelasi antara skor masing-masing butir pertanyaan dengan total skor. Jika korelasi antara skor masing-masing butir pertanyaan dengan total skor mempunyai tingkat signifikansi dibawah 0,05 , maka butir pertanyaan tersebut dinyatakan valid dan sebaliknya (Ghozali, 2009:49). Uji realibilitas data menggunakan metodeCronbach's Alpha. Suatu pertanyaan dapat dikategorikan reliabel jika nilai alpha lebih besar dari 0,6 (Nunnaly (1967) dalam Ghozali (2011: 48)).Metode pengujian hipotesis menggunakanmetode anilisis jalur (Path Analaysis). Untuk menguji hipotesis dalam penelitian ini, digunakan model penelitian sebagai berikut:
$\mathrm{PABP}=\mathrm{b} 1 \mathrm{PPGUG}+\mathrm{e} 1$
$\mathrm{KM}=\mathrm{b} 1 \mathrm{PPGUG}+\mathrm{b} 2 \mathrm{PABP}+\mathrm{e} 2$

Keterangan: PPGUG = Prinsip-Prinsip Good University Governance; $\mathrm{PAPB}=$ Pengelolaan Anggaran Berbasis Partisipatif; KM = Kinerja Manajerial; $\mathrm{b}_{1}-\mathrm{b}_{2}=$ Koefisien; $\mathrm{e}=$ error term .

\section{HASIL DAN PEMBAHASAN}

Tingkat Pengembalian Kuesioner dan Profil Responden. Dari 100 kuesioner yang distribusikan, 73 kuesioner yang kembali, 13 kuesioner yang datanya tidak dapat diolah karena datanya kurang lengkap, dan hanya 60 kuesioner yang datanya lengkap dan dapat diolah. Dengan kata lain, tingkat pengembalian kuesioner (response rate) sebesar 73\%.Pada Tabel 1 disajikan profil responden berdasarkan posisi jabatan.

Tabel 1. Deskripsi Profil Responden Berdasarkan Jabatan

\begin{tabular}{lrrrr}
\hline \multicolumn{1}{c}{ Jabatan } & Frequency & Percent & $\begin{array}{c}\text { Valid } \\
\text { Percent }\end{array}$ & $\begin{array}{c}\text { Cumulative } \\
\text { Percent }\end{array}$ \\
\hline Wakil Rektor & 1 & 1,7 & 1,7 & 1,7 \\
Wakil Dekan & 12 & 20,0 & 20,0 & 21,7 \\
Ketua Prodi & 14 & 23,3 & 23,3 & 45,0 \\
Kepala Biro & 1 & 1,7 & 1,7 & 46,7 \\
Kepala Bagian & 9 & 15,0 & 15,0 & 61,7 \\
Kepala Subag & 21 & 35,0 & 35,0 & 96,7 \\
SPI & 2 & 3,3 & 3,3 & 100,0 \\
Total & 60 & 100,0 & 100,0 & \\
\hline
\end{tabular}

Sumber: Data primer yang diolah

Dari Tabel 1 dapat diketahui bahwa responden yang berpartisipasi dalam penelitian ini yang menempati jabatan sebagai Wakil Rektor sebanyak 1 orang (1,7\%), Wakil Dekan sebanyak 12 orang (20\%), Ketua Prodi sebanyak 14 orang $(23,3)$, Kepala Biro sebanyak 1 orang $(1,7 \%)$, Kepala Bagian sebanyak 9 orang (15\%), Kepala Sub Bagian sebanyak 21 orang (35\%), dan Direktorat Sistem Pengendalian Intern sebanyak 2 orang $(3,3 \%)$.

Deskripsi Variabel. Deskripsi data pada setiap variabel penelitian disajikan dalam Tabel 2. Berdasarkan data pada Tabel 2dapat diketahui bahwa dari 60 responden yang mengisi kuesioner, pada variabel Partisipasi Anggaran jawaban minimum responden sebesar 11 dan maksimum sebesar 30, dengan rata-rata total jawaban 20,07 dan standar deviasi sebesar 4,957. 
Amilin: Dampak Penerapan Good University Governance Terhadap Kinerja Manajerial...

Tabel 2. Deskripsi Profil Data Variabel Penelitian

\begin{tabular}{llrrrr}
\hline \multicolumn{1}{c}{$\begin{array}{c}\text { Nama } \\
\text { Variabel }\end{array}$} & N & Min. & Max. & Mean & $\begin{array}{c}\text { Std. } \\
\text { Deviation }\end{array}$ \\
\hline Partisipasi Anggaran & 60 & 11 & 30 & 20,07 & 4,957 \\
Kinerja Manajerial & 60 & 21 & 42 & 33,05 & 4,284 \\
Good University Governance & 60 & 13 & 25 & 19,30 & 2,676 \\
Valid N (listwise) & 60 & & & & \\
\hline Sulw
\end{tabular}

Sumber: Data primer yang diolah

Pada variabel Kinerja Manajerial jawaban minimum responden sebesar 21 dan maksimum sebesar 42, dengan rata-rata total jawaban 33,05 dan standar deviasi sebesar 4,284. Sedangkan pada variabel Good University Governancejawaban minimum responden sebesar 13 dan maksimum sebesar 25, dengan rata-rata total jawaban 19,30 dan standar deviasi sebesar 2,676.

Hasil Uji Kualitas Data. Uji kualitas data terdiri dari dua kali pengujian yaitu: uji validitas data dan uji reliabilitas data. Berikut ini disajikan hasil uji validitas data dan hasil uji reliabilitas data. Data berikutini merupakan hasil uji validitas dari tiga variabel yang digunakan dalam penelitian ini, yaitu Good University Governance (GUG), Partisipasi Anggaran (PA), dan Kinerja Manajerial (KK). Pada Tabel 3 berikut ini disajikan hasil uji validitas data untuk variabel Good University Governance.

Tabel 3. Hasil Uji Validitas Variabel Good University Governance

\begin{tabular}{cccc}
\hline $\begin{array}{c}\text { Item } \\
\text { Pertanyaan }\end{array}$ & $\begin{array}{c}\text { Pearson } \\
\text { Correlation }\end{array}$ & $\begin{array}{c}\text { Sig. } \\
\text { (2-tailed) }\end{array}$ & Keterangan \\
\hline 1 (GUG1) & $0,811^{* *}$ & 0,000 & Valid \\
(GUG2) & $0,795^{* *}$ & 0,000 & Valid \\
(GUG3) & $0,714^{* *}$ & 0,000 & Valid \\
5 (GUG4) & $0,693 * *$ & 0,000 & Valid \\
\hline
\end{tabular}

**. Correlation is significant at the 0.01 level (2-tailed)

Sumber: Data primer yang diolah

Berdasarkan Tabel 3dapat diketahui bahwa item-item pertanyaan pada variabel Good University Governance dinyatakan validkarena semua item pertanyaan memiliki nilai korelasi yang signifikan pada tingkat 0,01 (2-tailed). Selanjutnya, pada Tabel 4berikut ini disajikan hasil uji validitas data untuk variabel Partisipatif Anggaran.

Tabel 4. Hasil Uji Validitas Variabel Partisipatif Anggaran

\begin{tabular}{crcc}
\hline Item & Pearson & Sig. & Keterangan \\
Pertanyaan & Correlation & (2-tailed) & \\
1 (PA1) & $0,763^{* *}$ & 0,000 & Valid \\
2 (PA2) & $0,824^{* *}$ & 0,000 & Valid \\
3 (PA3) & $0,833^{* *}$ & 0,000 & Valid \\
4 (PA4) & $0,881^{* *}$ & 0,000 & Valid \\
5 (PA5) & $0,854^{* *}$ & 0,000 & Valid \\
6 (PA6) & $0,856^{* *}$ & 0,000 & Valid \\
\hline
\end{tabular}


**. Correlation is significant at the 0.01 level (2-tailed)

Sumber: Data primer yang diolah

Dari Tabel 4 dapat diketahui bahwa item-item pertanyaan pada variabel Partisipatif Anggaran dinyatakan validkarena semua item pertanyaan memiliki nilai korelasi yang signifikan pada tingkat 0,01 (2-tailed).Terakhir, pada Tabel 5berikut ini disajikan hasil uji validitas data untuk variabel Kinerja Manajerial.

Tabel 5. Hasil Uji Validitas Variabel Kinerja Manajerial

\begin{tabular}{ccrr}
\hline $\begin{array}{c}\text { Item } \\
\text { Pertanyaan }\end{array}$ & $\begin{array}{c}\text { Pearson } \\
\text { Correlation }\end{array}$ & $\begin{array}{c}\text { Sig. } \\
\text { (2-tailed) }\end{array}$ & Keterangan \\
\hline 1 & $0,754^{* *}$ & 0,000 & Valid \\
2 & $0,733^{* *}$ & 0,000 & Valid \\
3 & $0,759^{* *}$ & 0,000 & Valid \\
4 & $0,554^{* *}$ & 0,000 & Valid \\
5 & $0,648^{* *}$ & 0,000 & Valid \\
6 & $0,537^{* *}$ & 0,000 & Valid \\
7 & $0,763^{* *}$ & 0,000 & Valid \\
8 & $0,711^{* *}$ & 0,000 & Valid \\
9 & $0,694^{* *}$ & 0,000 & Valid \\
\hline
\end{tabular}

**. Correlation is significant at the 0.01 level (2-tailed)

Sumber: Data primer yang diolah

Dari Tabel 5dapat diketahui bahwa item-item pertanyaan pada variabel Kinerja Manajerial dinyatakan validkarena semua item pertanyaan memiliki nilai korelasi yang signifikan pada tingkat 0,01 (2-tailed).

Hasil Uji Reliabilitas Data. Uji reliabilitas data dilakukan untuk menilai konsistensi instrumen penelitian. Sebuah instrumen penelitian dapat dikatakan reliabel jika nilai Cronbach Alpha berada diatas 0,6. Pada Tabel 6berikut disajikan hasil uji reliabilitas variabel-variabelpada penelitian ini.

Tabel 6. Hasil Uji Reliabilitas Variabel Penelitian

\begin{tabular}{clcl}
\hline No & \multicolumn{1}{c}{ Nama Variabel } & $\begin{array}{c}\text { Crobach's } \\
\text { Alpha }\end{array}$ & Keterangan \\
\hline 1 & Good University Governance & $0,797^{* *}$ & Reliabel \\
2 & Partisipasi Anggaran & $0,795^{* *}$ & Reliabel \\
3 & Kinerja Manajerial & $0,767 * *$ & Reliabel \\
\hline
\end{tabular}

Sumber: Data primer yang diolah

Dari Tabel 6dapat diketahui bahwa semua variabel yang diujikandalam penelitian ini dinyatakan reliable karena nilai Cronbach Alpha berada diatas 0,6.

Hasil Uji Hipotesis. Berdasarkan hasil pengujian data, Tabel 7berikut ini menyajikan hasil pengolahan data untuk menyusun Model Persamaan 1: 
Tabel 7. Ouput Statistik untuk Menyusun Koefisien Jalur Persamaan 1

\begin{tabular}{|c|c|c|c|c|c|c|}
\hline \multicolumn{7}{|c|}{ Coefficients $^{\mathrm{a}}$} \\
\hline \multirow{2}{*}{\multicolumn{2}{|c|}{ Model }} & \multicolumn{2}{|c|}{$\begin{array}{c}\text { Unstandardized } \\
\text { Coefficients }\end{array}$} & \multirow{2}{*}{$\begin{array}{c}\text { Standardized } \\
\text { Coefficients }\end{array}$} & \multirow[t]{2}{*}{$\mathrm{t}$} & \multirow[t]{2}{*}{ Sig. } \\
\hline & & B & Std. Error & & & \\
\hline \multirow{2}{*}{1} & (Constant) & 21,446 & 4,734 & & 4,530 & ,000 \\
\hline & GUG &,- 071 & ,243 &,- 039 &,- 294 & ,770 \\
\hline
\end{tabular}

a. Dependent Variable: PA

Sumber: Data primer yang diolah

Dari data yang ada pada Tabel 7diatas dapat diketahui bahwa nilai beta pada variabel Good University Governance pada persamaan (1) sebesar -0,039 dengan nilai signifikansi sebesar 0,770.Ini berarti bahwa variabel Good University Governance tidak mempengaruhi Partisipasi Anggaran. Nilai standardized beta sebesar -0,039 merupakan nilai path atau jalur $\mathrm{p} 2$.

Selanjutnya, pada Tabel 8 berikut ini disajikan hasil outpus SPSS untuk menyusun model persamaan 2:

Tabel 8. Ouput Statistik untuk Menyusun Koefisien Jalur Persamaan 2

Coefficients $^{\mathbf{a}}$

\begin{tabular}{|c|c|c|c|c|c|c|}
\hline \multicolumn{2}{|c|}{ Model } & \multicolumn{2}{|c|}{ Unstandardized Coefficients } & \multirow{2}{*}{$\begin{array}{c}\text { Standardized } \\
\text { Coefficients } \\
\text { Beta }\end{array}$} & \multirow[t]{2}{*}{$\mathrm{t}$} & \multirow[t]{2}{*}{ Sig. } \\
\hline & & $\mathrm{B}$ & Std. Error & & & \\
\hline & (Constant) & 19,584 & 4,338 & & 4,514 &, 000 \\
\hline \multirow[t]{2}{*}{1} & $\mathrm{PA}$ & ,008 & 103 & 009 & ,078 & ,938 \\
\hline & GUG & 689 & 192 & 431 & 3,600 &, 001 \\
\hline
\end{tabular}

a. Dependent Variable: KM

Sumber: Data primer yang diolah

Dari data yang ada pada Tabel 8dapat diketahui bahwa pada persamaan (2), nilai beta variabel Partisipatif Anggaran sebesar 0,009 dengan nilai signifikansi sebesar 0,938, sedangkan nilai beta variabel Good University Governance sebesar 0,431 dengan nilai signifikansi sebesar 0,001. Dari temuan ini dapat dimaknai bahwa variabel Partisipatif Anggaran tidak berpengaruh terhadap variabel Kinerja Manajerial, sedangan variabel Good University Governance berpengaruh terhadap variabel Kinerja Manajerial. Nilai standardized beta variabel Partisipatif Anggaransebesar 0,009 merupakan nilai path atau jalur p1, sedangkan Nilai standardized beta variabel Good University Governance sebesar 0,431 merupakan nilai jalur path 3 .

Untuk menghitung besarnya nilai e1 dapat dilihat pada Tabel 9. Dari Tabel 9 dapat dihitung nilai e1. Besarnya nilai e1 $=(1-0,001)^{2}=0,998$. Dengan demikian, besarnya nilai e1 adalah 0,998. Untuk menghitung besarnya nilai e2 dapat dilihat pada Tabel 10 di bawah ini: 
Tabel 9. Ouput Statistik untuk Menghitung Nilai e1

\begin{tabular}{lrrrrr}
\multicolumn{7}{c}{ Model Summary $^{\mathbf{b}}$} \\
\hline Model & R & R Square & \multicolumn{1}{c}{$\begin{array}{c}\text { Adjusted R } \\
\text { Square }\end{array}$} & $\begin{array}{l}\text { Std. Error of } \\
\text { the Estimate }\end{array}$ & $\begin{array}{l}\text { Durbin- } \\
\text { Watson }\end{array}$ \\
\hline 1 &, $039^{\text {a }}$ &, 001 &,- 016 & 4,996 & 1,640 \\
\hline
\end{tabular}

a. Predictors: (Constant), GUG

b. Dependent Variable: PA

Tabel 10. Ouput Statistik untuk Menghitung Nilai e2

\begin{tabular}{|c|c|c|c|c|c|}
\hline \multirow[b]{2}{*}{ Model } & \multicolumn{5}{|c|}{ Model Summary ${ }^{\mathbf{b}}$} \\
\hline & $\mathrm{R}$ & R Square & $\begin{array}{c}\text { Adjusted R } \\
\text { Square }\end{array}$ & $\begin{array}{l}\text { Std. Error of } \\
\text { the Estimate }\end{array}$ & $\begin{array}{l}\text { Durbin- } \\
\text { Watson }\end{array}$ \\
\hline 1 &, $430^{\mathrm{a}}$ &, 185 &, 157 & 3,934 & 2,067 \\
\hline
\end{tabular}

a. Predictors: (Constant), GUG, PA

b. Dependent Variable: KM

Dari Tabel 10 dapat dihitung nilai e2. Besarnya nilai e2 $=(1-0,185)^{2}=0,664$. Dengan demikian, besarnya nilai e 2 adalah 0,664 . Berdasarkan hasil perhitungan pada persamaan pertama dan persamaan kedua, serta penghitungan untuk memperoleh nilai e1 dan nilai e2, maka dapat diperoleh model analisis jalur seperti yang disajikan dalam gambar berikut ini:

$$
\mathrm{e} 1=0,998
$$

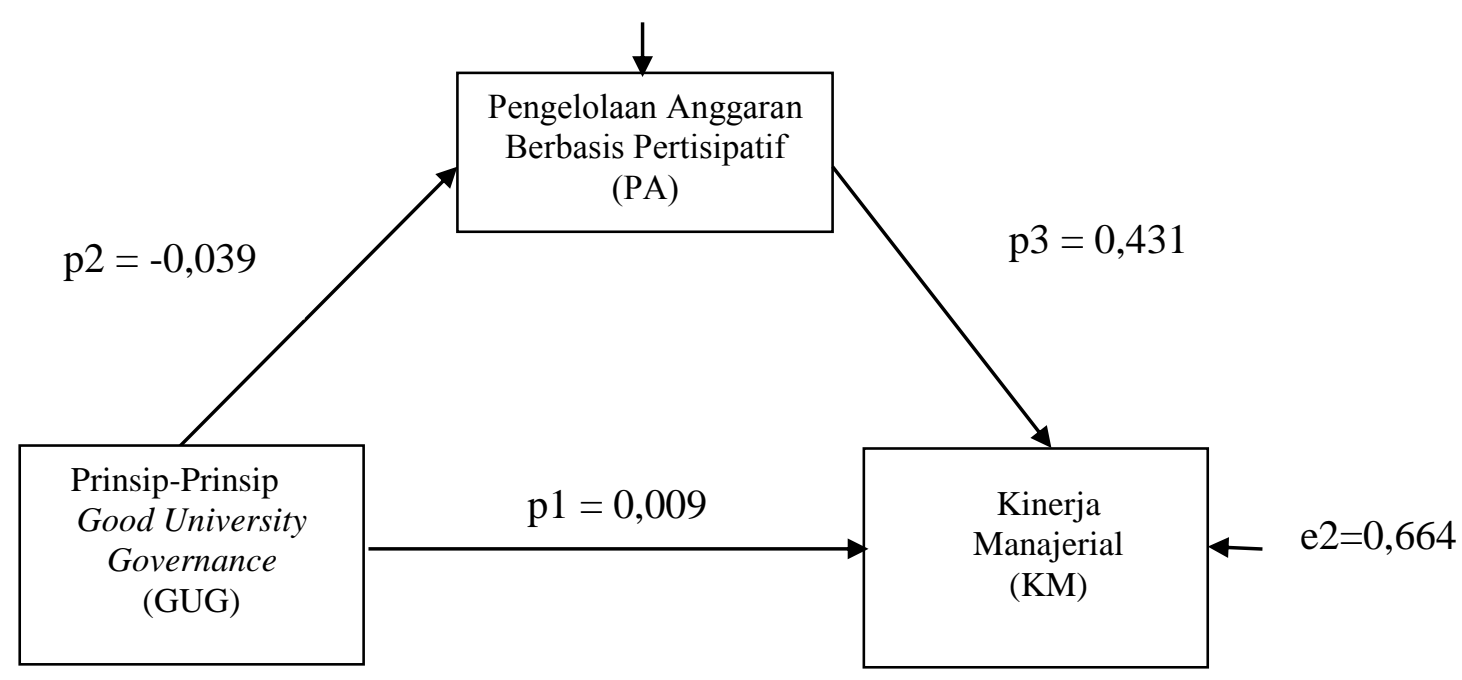

Gambar 1. Hasil Pengujian Menggunakan Analisis Jalur

Dari model analisis jalur pada Gambar 1, dapat diketahui bahwa variabel PrinsipPrinsip Good University Governance memiliki hubungan langsung dengan variabel Kinerja Manajerial dengan nilai P1 sebesar 0,009, sehingga hipotesis pertama yang menyatakan bahwa: "Penerapan prinsip-prinsip Good University Governance berpengaruh 
terhadap kinerja manajerial" dapat didukung. Temuan ini dapat dimaknai bahwa implementasi Prinsip-prinsip Good University Governancedi UIN Syarif Hidayatullah Jakarta dapat berpengaruh positif terhadap Kinerja Manajerial.

Selanjutnya, untuk mengetahui apakah variabel Pengelolaan Anggaran Berbasis Partisipatif dapat berperan atau tidak sebagai variabel intervening, dapat diketahui melalui perhitungan berikut ini: nilai p2 X nilai p3 > nilai p1. Berdasarkan hasil perhitungan dengan menggunakan formula tersebut maka dapat diketahui bahwa variabel Pengelolaan Anggaran Berbasis Partisipatif dapat berperan sebagai variabel intervening dalam modelpenelitian ini. Hasil pengujian lainnya menunjukkan bahwa variabel Prinsip-Prinsip Good University Governance tidak dapat berperan sebagai variabel intervening. Berikut ini hasil perhitungannya: $\mathrm{p} 2 \mathrm{X}$ Nilai p3 $>$ nilai $\mathrm{p} 1=-0,039 \mathrm{X} 0,431<0,009$, atau $-0,017<$ 0,009. Dari perhitungan tersebut dapat diketahui bahwa hipotesis kedua tidak dapat didukung. Dengan demikian, hipotesis yang menyatakan: "Penerapan prinsip-prinsip Good University Governance berpengaruh terhadap kinerja manajerial melalui praktik pengelolaan anggaran berbasis partisipatif sebagai variabel intervening" tidak dapat didukung.

Pembahasan. Dari hasil pengujian dapat diketahui bahwa variabel Prinsip-Prinsip Good University Governanceberpengaruh positif terhadap variabel Kinerja Manajerial. Ini artinya, dengan diterapkan Prinsip-Prinsip Good University Governance, maka dapat meningkatkan Kinerja Manajerial. Semakin baik penerapan Prinsip-Prinsip Good University Governance maka kinerja manajerial di UIN Syarif Hidayatullan semakin meningkat. Temuan ini selaras dengan apa yang dinyatakan oleh Anthony \&Govindarajan (2007)yang menyebutkan bahwa anggaran berfungsi untuk mengkoordinasikan rencana jangka pendek, untuk melakukan komunikasi, memotivasi, dan upaya pengendalian sehingga dapat menghasilkan komitmen sebagai dasar penilaian kinerja manajer. Fungsifungsi tersebut dapat tercapai jika dalam proses penyusunannya melibatkan semua elemenorganisasi yang melaksanakan anggaran tersebut.

Temuan ini juga konsisten dengan hasil penelitian yang dilakukan oleh Argyris (1975), dimana anggaran berfungsi sebagai alat pengendalian yang dapat memotivasi para anggota organisasi dalam meningkatkan kinerja manajerialnya.Jika dikaitkan dengan implementasi konsep Good University Governance, Wijatno (2009) menyatakan bahwa prinsip GCG dapat diterapkan dalam mengelola sebuah perguruan. Hal ini diperkuat oleh pendapatDarmawati, Khomsiyah dan Rahayu(2004) yang menyatakan bahwaGood Governance dapat memfasilitasi penentuan sasaran-sasaran organisasi, sekaligus sebagai sarana untuk menentukan teknik monitoring kinerja manajerial. Dengan demikian, UIN Syarif Hidayatullah sebagai sebuah institusi pendidikan tinggi yang menerapkan prinsipprinsip Good University Governance sangat relevan ketika para pimpinannya menghendaki pencapaian kinerja manajerial terbaik.

Temuan yang kedua menunjukkan bahwa praktik pengelolaan anggaran berbasis partisipatif tidak berhasil dalam memediasi pengaruh penerapan prinsip-prinsip Good University Governance terhadap Kinerja Manajerial. Temuan ini tidak konsisten dengan studi yang dilakukan oleh Milani (1975) yang menunjukkan bahwa tingkat keterlibatan bawahan dalam pembuatan keputusan pada proses penyusunan anggaran merupakan faktor utama yang membedakan antara penganggaran partisipatif dengan penganggaran non-partisipatif. Hal ini selaras dengan pendapat Stedry (1960) yang menyatakan bahwa aspirasi bawahan lebih diperhatikan dalam proses penyusunan anggaran partisipatif 
sehingga lebih memungkinkan bagi bawahan melakukan negosiasi dengan atasan mengenai target anggaran yang menurut mereka dapat dicapai.

Tidak konsistennya temuan kedua ini dengan temuan pada studi sebelumnya mungkin disebabkan oleh beberapa hal, salah satunya seperti yang diungkapkan oleh Brownell (1992) yang menyatakan bahwa partisipasi pada dasarnya merupakan proses organisasional, para anggota organisasi yang terlibat dalam proses pembuatankeputusan memiliki kepentingan dengan para stakeholders. Partisipasi dalam konteks penyusunan anggaran merupakan proses individu yang kinerjanya dievaluasi berdasar pencapaian anggaran. Seperti kita ketahui, UIN Syarif Hidayatullah merupakan sebuah satuan kerja di bawah Kementerian Agama, memiliki pedoman penyusunan anggaran yang menggunakan dana APBN dan dana Non APBN. Aturannya sangat rigid dan pelaporan atas penggunaanya sangat ketat, sehingga meskipun partisipasi pada pejabat level lebih bawah dilibatkan, namun dalam pelaksanaannya tidak fleksibel seperti yang dijalankan pada organisasi non Pemerintah(khususnya pada perusahaan swasta), sehingga partisipasi di lingkungan UIN Syarif Hidayatullah Jakarta tidak dapata diterapkan secara maksimal.

Seperti dinyatakan sebelumnya oleh Argyris (1952) dan Milani(1975) bahwa proses penyusunan anggaran suatu organisasi merupakan kegiatan yang penting dan komplek, karena berdampak terhadap sikap dan perilaku anggota organisasi. Hal inidipertegas oleh Brownell (1982) yang menyatakan bahwa ada beberapa penelitian yang menguji hubungan antara partisipasi anggaran dengan kinerja manajerial yang memperoleh hasil tidak konsisten.Hasil penelitian ini juga mengkonfirmasi pernyataan Brownell (1982) tersebut. Tidak konsistennya temuan kedua pada hasil penelitian ini diduga dipengaruhi oleh faktor lain, misalnya disebabkan oleh variabel gaya kepemimpinan yang ada di organisasi UIN Syarif Hidayatullan Jakarta. Analisa ini dipertegas oleh hasil studi yang dilakukan Indriantoro (1993) yang melakukan studi tentang proses penyusunan anggaran yang dikaitkan dengan variabel gaya kepemimpinan.Hasil studi lndriantoro (1993) tersebut menujukkan bukti bahwa gaya seorang pimpinan organisasi dapat berpengaruh terhadap proses penyusunan anggaran.Oleh karena itu, temuan hasil studi pada penelitian ini penting bagi para pejabat universitas/sekolah tinggi/institut sebagai referensi dalam melakukan pengelolaan anggaran berbasis partisipatif dengan menerapkan prinsip-prinsip Good University Governance untuk mencapai kinerja yang terbaik.

\section{PENUTUP}

Simpulan. Penelitian inibertujuan untuk memperoleh bukti empiris tentang dampak penerapan prinsip-prinsip Good University Governance terhadap kinerja manajerial dalam praktik pengelolaan anggaran berbasis partisipatif pada UIN Syarif Hidayatullah Jakarta. Responden yang berpartisipasi dalam penelitianini dan memenuhi kriteria untuk dilakukan pengujian sebanyak 60orang yang memiliki jabatan struktural di UIN Syarif Hidayatullah pada posisi: Wakil Rektor, Wakil Dekan, Ketua Program Studi, Kepala Biro, Kepala Bagian, Kepala Sub Bagian, dan Direktorat Sistem Pengendalian Intern. Berdasarkan hasil analisisdata dengan menggunakan analisis jalur diperoleh dua kesimpulan sebagai berikut: Pertama, penerapan prinsip-prinsip Good University Governance di UIN Syarif Hidayatullah Jakarta berpengaruh terhadap kinerja manajerial. Kedua, praktik pengelolaan anggaran berbasis partisipatif di UIN Syarif Hidayatullah Jakarta belum dapat mendorong 
penerapan prinsip-prinsip Good University Governancedalam mempengaruhi kinerja manajerial.

Keterbatasan. Penelitianinisetidaknya dihadapkan pada dua keterbatasan, diantaranya adalah sebagai berikut.Pertama, belum melibatkan rektor sebagai responden dalam penelitian ini, padahal rektor adalah pimpinan perguruan tinggi yang memiliki jabatan strategis dalam menentukan kebijakan dan penerapan Good University Governance yang terkait dengan diterapkannya kebijakan praktik pengelolaan anggaran berbasis partisipatif dan peningkatan kinerja manajerial.Kedua, perolehan data belum menggambarkan informasi secara mendalam mengenai penerapan Good University Governance yang terkait dengan diterapkannya kebijakan praktik pengelolaan anggaran berbasis partisipatif dan peningkatan kinerja manajerial, hal ini disebabkan karena metode pengumpulan data masih menggunakan survey melalui penyebaran kuesioner.

Rekomendasi. Penelitian sejenis di masa mendatang diharapkandapatmenyajikanhasil penelitianyang lebihmendalamdengan memperhatikan dua rekemondasi sebagai berikut:Pertama, melibatkan rektor sebagai responden dalam penelitian ini, karena rektor merupakan pimpinan perguruan tinggi yang memiliki jabatan strategis dalam menentukan kebijakan dan penerapan Good University Governance yang terkait dengan diterapkannya kebijakan praktik pengelolaan anggaran berbasis partisipatifmaupun upaya peningkatan kinerja manajerial sehingga mendapat informasi yang lebih komprehensif.Kedua, penelitian berikutnya disarankan selain menggunakan metode survey melalui kuesioner,juga perlu dilengkapidengan menggunakan metode indepth interview, agar dapat memperoleh informasi secara lebih mendalam mengenai penerapan Good University Governance yang terkait dengan diterapkannya kebijakan praktik pengelolaan anggaran berbasis partisipatifyang dapat berdampak terhadap peningkatan kinerja manajerial.

\section{DAFTAR RUJUKAN}

Argyris, C. (1952) The Impact of Budgeting on People. Controllership Foundation Inc., New York.

Anthony, R. N. and Govindarajan, V. (2007) Management Control System. McGraw-Hill Education: Irwin.

Atkinson, R. L., Atkinson, R.C. (1997) Introduction to Psychology, Eighth Edition. Edisi Terjemah. Penerbit Erlangga, Jakarta.

Birnberg, J. G., \& Snodgrass, C. (1988) Culture and Control: A Field Study. Accounting, Organizations and Society, 13, 447-464.

Brownell, P. \& McIrmes, M. (1986) Budgetary Participation, Motivation, and Managerial Performance. The Accounting Review (October), 587-600.

Brownell, P. (1992) "Participation in the Budgeting Process - When it Works and When it Doesn't". Journal of Accounting Literature, 124-153 (Spring).

Blanchette, D., Pilote, C. And Cadieux, J. (2002) Manager's Moral Evaluation of Budgetary Slack Creation. The Accounting Review. Vol 26: 141-162.

Brownell, P. (1982) "The Role of Accounting Data in Performance Evaluation, Budgetary Participation, and Organizational Effectiveness". Journal of Accounting Research (Spring), 12-27. 
Chow, C., J. Cooper and W. Waller (1991) Participative Budgeting: Effects of a TruthInducing Pay Scheme and Information Asymmetry on Slack and Performance. The Accounting Review. Vol 63: 111-122.

Chong, V. K., and Chong, K. M. (2002) Budget Goal Commitment and Informational effect of Budget Participation on Performance: A Structural equation Modelling Approach, Vol.14, pp. 65-86.

Clinton, D. and Hunton, J. (2001) Linking Participative Budgeting Congruence to Organization Performance. Behavioral Research In Accounting, Vol. 13, page 127141.

Darmawati, D., Khomsiyah dan Rahayu, R.K. (2004) Hubungan Corporate Governance dan Kinerja Perusahaan. Simposium Nasional Akuntansi VII, IAI, 2004.

Dunk, A. S. (1993) The Effect of Budget Emphasis and Information Asymmetry on the Relation Beetween budgetary participation and Slack. The Accounting Review No. 68: 400-410.

Dunk, A., dan Nouri, H. (1998) Antecedents of Budgetary Slack: A Literature Rreview and Synthesis. Journal of Accounting Literature 17: 72-96.

Dunk, A.S. and Perera, H. (1996) "The Incidence of Budgetary Slack: A Field Study Exploration. Accounting", Auditing and Accountability Journal, No. 10 (5), 649664.

Fama, E. (1980) "Agency problem and the theory of the business". Journal of Political Economy 88, 134-145.

Fama, E., \& Jensen, M., (1983) "Separation of Ownership and Control". Journal of Law and Economics, 26, 301-325.

Ferris, K.R. (1977) A Test of The Expectancy Theory of Motivation in an Accounting Environment. The Accounting Review LII (3), 605-615.

Fisher, J.G., Frederickson, J.R. and Peffer,S.A. (2000) Budgeting: An Experimental Investigation of The Effects of Negotiationl. The Accounting Review, Vol.75 (1). Pp. 93-114.

Garrison, G. L. dan Noreen, N. (2003) Akuntansi Manajerial, Edisi Terjemah, Jakarta: Salemba Empat.

Ghozali, I. (2011) Aplikasi Analisis Multivariat dengan Program SPSS. Balai Penerbit Universitas Dipenogoro, Semarang.

House, R. L. (1971) A Path Goal Theory of Leader Effectiveness, Administrative Science Quarterly pp. 321-339.

Harrison, G. L. (1992) The Cross-Cultural Generalizability of the Relation Between Participation, Budget Emphasis and Job Related Attitudes. Accounting, Organizations and Society, 17 (1), 1-15.

Hopwood, A. (1976) Accounting and Human Behaviour. Englewood Cliffs, New Jersey: Prentice-Hall.

Hofstede, G. (1994) Harper Collins Publishers.

Hwang, S. C. (1989) The Effectof Culture on the Relationship between Participation and Motivation, Unpublished Ph.D dissertation, Macquarie University.

Indriantoro, N. (1993) The Effect of Participative Budgeting on Job Performance and Job Satisfaction with Locus of Control and Cultural Dimensions as Moderating Variable. Dissertation. 
Ivancevich, J.M. (1979) “An Analysis of Participation in Decision Making Among Project Engineers". Academy of Management Journal 22 (2), 253-269.

Kaplan, R.S.; Cooper, R. (1998) Cost \& Effect. Using Integrated Cost Systems to Drive Profitability and Performance, Harvard Business School Press.

Kren, L. (1992) Budgetary Participation and Managerial Performance: The Impact of Information and Environmental Volatility. The Accounting Review, 67, 511-526.

Milani, K. R. (1972) Budgeting in an Industrial Setting: A Field Study of the Relationship Between Involvement in Budget-setting and Job Performance and Attitudes, unpublished Ph.D. Thesis, The University of Iowa.

(1975) The Relationship of Participation in Budget Setting to Industrial Supervisor Performance and Attitudes: a Field Study. The Accounting Review 50, 274-284.

Mahoney, T. A., Jerdee, T. H. and Carroll, S. J. (1963) Development of Managerial Performance: A Research Approach, Cincinnati: South Western Publ. Co.

Otley, D. T. (1978) Budget Use and Managerial Performance. Journal of Accounting Research (Spring 1978). pp 122-149.

Stedry, A. C. (1960) Budget Control and Cost Behavior, Englewood Clifft, NJ: PrenticeHall.

Steven, D. E. (2002) The Effects of Reputation and Ethics on Budgetary Slack. Journal of Management Accounting Research 14: 153-171.

Syakhroja, A. (2003) Political Games in Budgeting Process of Goverment Manufacturing Enterprises in Indonesia: A Qualitative Approach, Usahawan No 5, Tahun XXXII, Mei.

Shield, M.D, Deng, J.F. and Kato, Y. (2000) The Design and Effects of Control Systems: Test of Direct and Indirect Effect Models, Accounting Organization and Society, Vol 25, pp 185-202.

Tsui, J. S. L. (2001) "The Impact of Culture on the Relationship Between Budgetary Participation, Management Accounting Systems, and Managerial Performance: An Analysis of Chinese and Western Managers". The International Journal of Accounting, 36, 125-146.

Ueno, S., \& Sekaran, U. (1992) "The Influence of Culture on Budget Control Practices in the USA and Japan: An Empirical Study". Journal of International Business Studies, 23(4), 659-674.

Utomo, S. B., (2006) Pengaruh Partisipasi Anggaran, Informasi Asimetris, dan Budget Emphasis Terhadap Senjangan Anggaran. Laporan Hasil Penelitian Tidak Dipublikasikan, FE Unsoed Purwokerto.

Wijatno, S. (2009) Pengelolaan Perguruan Tinggi Secara Efisien, Efektif, dan Ekonomis. Penerbit Salemba Empat. Jakarta.

Wentzel, K. (2002) "The Influence of fairness Perceptions and Goal Commitment on Managers' Performance in a Budget Setting”, Behavioural Research in Accounting, Vol.14, pp. 247-271.

Yenti, R.R. (2003) Pengaruh Keadilan Distributif, Keadilan Prosedur, Komitmen terhadap Tujuan, dan Motivasi terhadap Kinerja Manajerial dalam Penyusunan Anggaran. Simposium Nasional Akuntansi VI: 707-720. 